\title{
Metaclassifiers for Predicting the Robotic Navigational Performance
}

\author{
S.Padmapriya, J.S. Richard Jimreeves, P.Kalaiselvi, A.Nageswaran, S.Arun
}

\begin{abstract}
Prediction of robot steps can be used in path exploring problems and application of data mining techniques, enhances navigational direction of robots. In this paper the proposed method is validated on the data sets using multi classification algorithms with four types of movement classes like Action-ahead, Sharp right turn, small in degree-right turn, and small in degree left turn in a separate layer. We obtain the results based on Meta classifiers' accuracies tabulated. A layered approach is followed for obtaining the more accurate multi-classification.
\end{abstract}

Keywords: Data Mining, Classifiers, Multiclass, Layered approach, Multi-Classificat

\section{INTRODUCTION}

This process discovers novel correction pattern and recent trends by shifting through the huge amount of data loaded in storehouse, Using this technique for statistical and analysis for pattern recognition. Process is deal with diagnosis of invisible knowledge through data mining unforeseen patterns and different rules from huge database.

Classifications are one of the most popular Data mining techniques. Classification predicts categorical discrete unordered labels. In the data mining we have a various types of classification techniques which are used such as Decision tree, Fuzzy logic, Meta-Classifier and so on.

The subject exposed in popularized briefly as given below, in part section 2, workout the problem. In part section 3, Analysis and results in experimental output, finally we conclude in part section 4 .

\section{ESTIMATING CLASSIFIER EFFICIENCY}

Supposing classifier efficiency is the most important to allow data to check the efficiency for a given classifier which will mark the future data. The main usage classifier which wraps to provide additional data preprocessing for feature selection accuracy. Some of the techniques for estimating

Revised Manuscript Received on September 22, 2019.

Dr.S.Padmapriya, Professor, CSE, Prathyusha Engineering College,

Chennai, India, email-id:padmapriya.it@prathyusha.edu.in

J.S. Richard Jimreeves, Assistant Professor, IT, Easwari Engineering College, Chennai, India. email-id: richardjimreeves@gmail.com

P.Kalaiselvi, Assistant Professor,CSE, PERI Institute of Technology, Chennai, India, email-id:kalaiselvicse19@gmail.com

Dr.A.Nageswaran, Associate Professor, Department of IT, Kings Engineering College,Irungattukottai,TamilNadu,India

email-id: nageswaraan@gmail.com

Dr.S.Arun, Professor, Department of ECE, Prathyusha Engineering College, Chennai, India. email-id: yesarun1810@gmail.com classifiers are $\mathrm{k}$ fold cross Validation methods and bootstrapping. In this paper, Meta Classification methods are implemented. Meta Classification algorithms are Bagging, Dagging, Decorate, AdaBoostM1, and Multi Scheme etc..,.

\section{PROPOSED LAYERED MODEL}

The main components of our model are classified into two stages, the first stage is to classify the dataset one of two or move forward, the second stage contains three different sequential layers which are able to identify three classes.

The dataset categorized into two sets one as 'Turn' another as 'Move Forward', then we implements the layered approach model.

It consists of three different sequential layers such as Layer(1), Layer(2) and Layer (3) which can identify three classes Whether sharp- right turn, small in degree- right turn, small in degree left turn. To improve high efficiency in second stage, this proposed model is bagging, decorate, multiclass classifier, multi-boost $\mathrm{AB}$.

Classification technique is one of the prominent to data mining process. Classification predicts categorical discrete unordered labels. In the data mining we have a various types of classification techniques which are used such as Decision tree, Fuzzy logic, Meta Classifier and so on.

\section{RESULT}

In given below the description of dataset is obtained from the UCI repository, all the data to consist of attributes collected the data from the sensor. SCITOS G5 is the navigation robot through the room follower wall in a clockwise direction, for four cycles, using of sensor ultrasound sensor arranged circularly around its waist.

\subsection{Navigation set Description}

The Robot Navigation datasets are collected from UCI repository. It navigates or directs the following clockwise direction. It has 4 divisions; using 24 sensors are arranged in circular format. It is in the form of .arff file format. This dataset contains three different files. Each contains a particular or unique reading which is used to evaluate to the work of classifiers with proper input In this we consider the first dataset as it contains more than 5000 attributes and instances. 


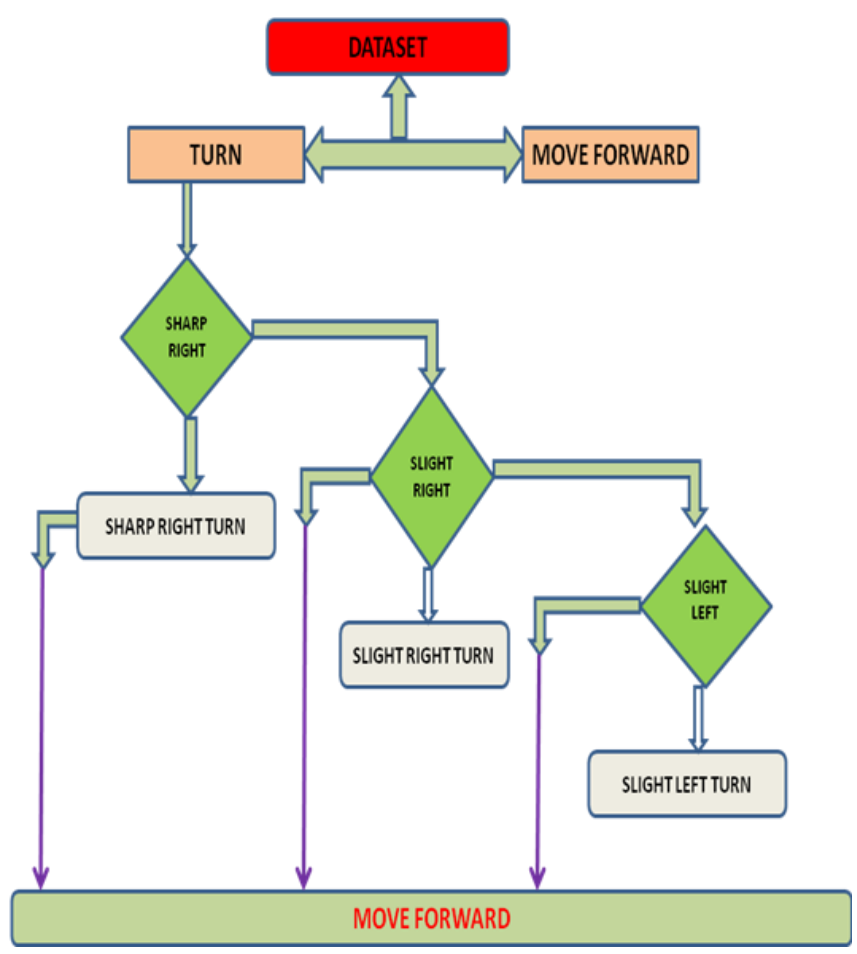

Figure 1 Layered-Model Approach System

\subsection{ATTRIBUTE DESCRIPTION}

Attributes contain 24 sensor readings and 24 numeric class of the attributes. To apply multi classification for a dataset with four types of movement classes like Action-ahead, Sharp right turn, small in degree-right turn, and small in degree left turn in a separate layer for 24 numeric attributes. The selection of attributes is based on input dataset, the searched of method is first Best with no input, start dataset no input forward direction with 5 node.

\begin{tabular}{|c|l|l|}
\hline Subset name & Algorithm & $\begin{array}{l}\text { Selected } \\
\text { attributed }\end{array}$ \\
\hline S1 & Best first & M,N,O,R,S,T \\
\hline S2 & $\begin{array}{l}\text { Exhaustive } \\
\text { Search }\end{array}$ & M,N,O,R,S,T \\
\hline S3 & Genetic search & M,N,O,R,S,T \\
\hline
\end{tabular}

Table 1 Selected Attributes

\subsection{TOOLS USED}

We have used in WEKA software, algorithm analysis and predictive modeling and easy to access the simulated in graphical representation and date preprocessing in front end and also database connectivity in form of GUI.

\subsection{PERFORMANCE EVALUATION}

Let the set of original attribute be $\mathrm{L}$ i.e( $\mathrm{L}=\{\mathrm{A}$ to $\mathrm{Y}\}$ While we try to reduce the attribute by eliminating insignificant attributes, Algorithm: 1.CfsSubsetEval attribute Selection BestFirst Original Attribute: $\mathrm{L}=\{$ a to $\mathrm{x}\}$ usage attribute is 90 to $100 \%$.

\subsubsection{Attribute selection}

\begin{tabular}{|c|l|c|c|}
\hline Layer No & Layer & $\begin{array}{c}\text { No. Of } \\
\text { attributes } \\
\text { selected }\end{array}$ & $\begin{array}{c}\text { Selected } \\
\text { Attributes }\end{array}$ \\
\hline 1 & $\begin{array}{l}\text { Sharp Right } \\
\text { Turn }\end{array}$ & 2 & N,O \\
\hline 2 & $\begin{array}{l}\text { Slight Right } \\
\text { Turn }\end{array}$ & 3 & N,S,T \\
\hline 3 & Slight Left Turn & 4 & Q,R,S,T,W \\
\hline
\end{tabular}

Table 2 Selected Attributes

\subsubsection{Classification with Stages}

There are two different classification stages, In the first stage the data as partitioned into either move forward or turn. In the second stage the following methods are used describe It consists of three different sequential layers such as Layer(1), Layer(2) and Layer (3) which can identify three classes Whether sharp- right turn, small in degree- right turn, small in degree left turn. To improve high efficiency in second the accuracy and it is implemented in layered approach system, the separate model for using $\mathrm{K}$ learning process. In this paper data mining algorithms are used.

4.4.3 Layer 1

\begin{tabular}{|c|c|c|}
\hline List of attribute & No of folds $\%$ & $\begin{array}{l}\text { Selected } \\
\text { attribute }\end{array}$ \\
\hline A & $0(0 \%)$ & - \\
\hline B & $0(0 \%)$ & - \\
\hline $\mathrm{C}$ & $0(0 \%)$ & - \\
\hline $\mathrm{D}$ & $0(0 \%)$ & - \\
\hline $\mathrm{E}$ & $0(0 \%)$ & - \\
\hline $\mathrm{F}$ & $0(0 \%)$ & - \\
\hline G & $0(0 \%)$ & - \\
\hline $\mathrm{H}$ & $0(0 \%)$ & - \\
\hline I & $0(0 \%)$ & - \\
\hline $\mathrm{J}$ & $0(0 \%)$ & - \\
\hline $\mathrm{K}$ & $0(0 \%)$ & - \\
\hline $\mathrm{L}$ & $0(0 \%)$ & - \\
\hline $\mathrm{M}$ & $10(100 \%)$ & $\checkmark$ \\
\hline $\mathrm{N}$ & $10(100 \%)$ & $\checkmark$ \\
\hline $\mathrm{O}$ & $10(100 \%)$ & $\checkmark$ \\
\hline $\mathrm{P}$ & $0(0 \%)$ & - \\
\hline Q & $0(0 \%)$ & - \\
\hline $\mathrm{R}$ & $10(100 \%)$ & $\checkmark$ \\
\hline $\mathrm{S}$ & $10(100 \%)$ & $\checkmark$ \\
\hline $\mathrm{T}$ & $10(100 \%)$ & $\checkmark$ \\
\hline $\mathrm{U}$ & $0(0 \%)$ & - \\
\hline V & $0(0 \%)$ & - \\
\hline $\mathrm{W}$ & $0(0 \%)$ & - \\
\hline$X$ & $0(0 \%)$ & - \\
\hline
\end{tabular}

Table 3 Classified Attributes 
In the first layer the dataset is mined for the pattern whether the robot's next step is turn or move forward, After detecting the 'turn'ing intension of the robot, In the second layer we have partitioned the dataset into either move forward or slight right. This layer is dedicated to emphasis on 'sharp right' behaviour.

Layer 1 is carried out as shown in fig1for classification. The classification accuracy is shown in Table3

\begin{tabular}{|c|l|l|l|l|}
\hline Sno & $\begin{array}{l}\text { Algorithm } \\
\text { Name }\end{array}$ & $\begin{array}{l}\text { Base } \\
\text { classifier } \\
\text { built }\end{array}$ & $\begin{array}{l}\text { Accurac } \\
\mathbf{y}\end{array}$ \\
\hline 1. & Bagging & REPTree & $\begin{array}{l}0.26 \\
\text { seconds }\end{array}$ & $96 \%$ \\
\hline 2. & Dagging & SMO & 1.42 seconds & $56 \%$ \\
\hline 3. & Decorate & J48 & 5.16 seconds & $90 \%$ \\
\hline 4. & $\begin{array}{l}\text { Multiclass } \\
\text { Classifier }\end{array}$ & Logistic & $\begin{array}{l}0.89 \\
\text { seconds }\end{array}$ & $63 \%$ \\
\hline 5. & MultiBoost AB & $\begin{array}{l}\text { Decision } \\
\text { Stump }\end{array}$ & $\begin{array}{l}0.45 \\
\text { seconds }\end{array}$ & $69 \%$ \\
\hline
\end{tabular}

Table 4 First Stage Classification

4.4.3.1 Sharp-Right-Turn Layer:

\begin{tabular}{|l|c|c|c|}
\hline \multicolumn{1}{|c|}{ Methods } & $\begin{array}{c}\text { Correctly } \\
\text { classified }\end{array}$ & $\begin{array}{c}\text { Incorrectly } \\
\text { classified }\end{array}$ & $\begin{array}{c}\text { Time to } \\
\text { built }\end{array}$ \\
\hline Bagging & $99.7617 \%$ & $0.2383 \%$ & $\begin{array}{c}0.94 \\
\text { seconds }\end{array}$ \\
\hline Dagging & $80.6085 \%$ & $19.3915 \%$ & $\begin{array}{c}1.15 \\
\text { seconds }\end{array}$ \\
\hline Decorate & $99.8167 \%$ & $0.1833 \%$ & $\begin{array}{c}23.73 \\
\text { seconds }\end{array}$ \\
\hline $\begin{array}{l}\text { Multiclass } \\
\text { Classifier }\end{array}$ & $80.187 \%$ & $19.813 \%$ & $\begin{array}{c}0.48 \\
\text { seconds }\end{array}$ \\
\hline $\begin{array}{l}\text { MultiBoost } \\
\text { AB }\end{array}$ & $91.0924 \%$ & $8.9076 \%$ & $\begin{array}{c}0.75 \\
\text { seconds }\end{array}$ \\
\hline
\end{tabular}

The right - turn layers are details shown in table 5

Table 5 Layer 1 Classification of Sharp_Right_Turn

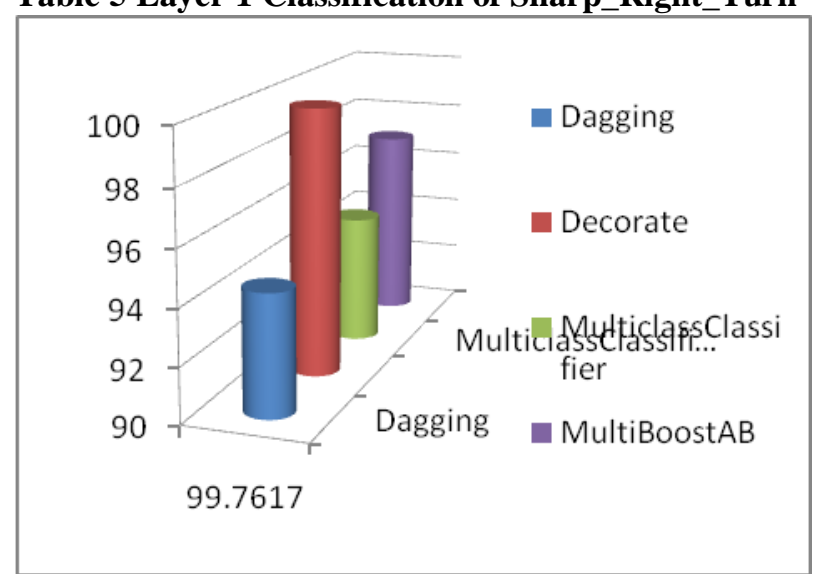

Figure 2 Performance comparison for Sharp-Right-Turn.

\subsubsection{Layer 2}

In the second layer we have partitioned the dataset into either move forward or slight right. This layer is dedicated to emphasis on 'slight right turn' behavior. Layer 2 is carried out as shown in fig1 for classification. The classification accuracy is shown in Table 2.

\subsubsection{Slight-Right-Turn Layer:}

The results of Stage 2 Slight-Right-Turn Layer are shown in table 6

\begin{tabular}{|l|c|c|c|}
\hline \multicolumn{1}{|c|}{ Methods } & $\begin{array}{c}\text { Correctly } \\
\text { classified }\end{array}$ & $\begin{array}{c}\text { Incorrectly } \\
\text { classified }\end{array}$ & $\begin{array}{c}\text { Time to } \\
\text { built }\end{array}$ \\
\hline Bagging & $99.6518 \%$ & $0.3482 \%$ & 0.94 seconds \\
\hline Dagging & $85.9604 \%$ & $14.0396 \%$ & 0.72 seconds \\
\hline Decorate & $99.5601 \%$ & $0.4399 \%$ & $\begin{array}{c}35.04 \\
\text { seconds }\end{array}$ \\
\hline $\begin{array}{l}\text { Multiclass } \\
\text { Classifier }\end{array}$ & $88.3431 \%$ & $11.6569 \%$ & 0.44 seconds \\
\hline $\begin{array}{l}\text { MultiBoost } \\
\text { AB }\end{array}$ & $90.6708 \%$ & $9.3292 \%$ & 0.94 seconds \\
\hline
\end{tabular}

Table 6 Layer 1 Classification of Slight_Right_Turn

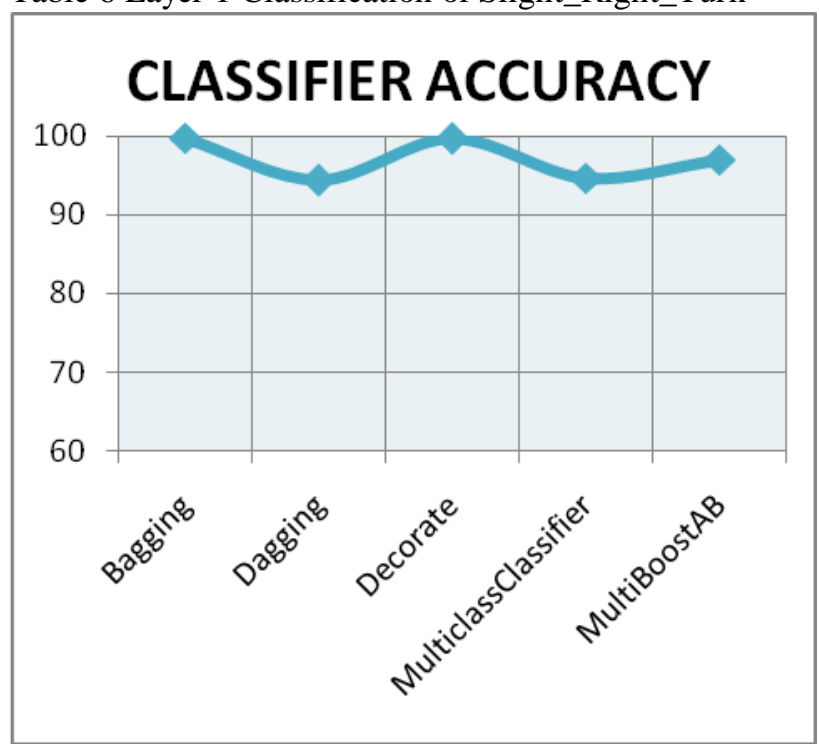

Figure 3 Performance comparison for Slight_Right_Turn emphasis on 'slight left turn' behavior.

4.4.5.1 Slight-Left-Turn Layer:

The results of Stage 2 Slight-Left-Turn Layer are shown in table 7 . 


\begin{tabular}{|l|c|c|c|}
\hline \multicolumn{1}{|c|}{ Methods } & $\begin{array}{c}\text { Correctly } \\
\text { classified }\end{array}$ & $\begin{array}{c}\text { Incorrectly } \\
\text { classified }\end{array}$ & $\begin{array}{c}\text { Time to } \\
\text { built }\end{array}$ \\
\hline Bagging & $99.7617 \%$ & $0.2383 \%$ & $\begin{array}{c}0.7 \\
\text { seconds }\end{array}$ \\
\hline Dagging & $94.3915 \%$ & $5.6085 \%$ & $\begin{array}{c}0.73 \\
\text { seconds }\end{array}$ \\
\hline Decorate & $99.7067 \%$ & $0.2933 \%$ & $\begin{array}{c}24.27 \\
\text { seconds }\end{array}$ \\
\hline $\begin{array}{l}\text { Multiclass } \\
\text { Classifier }\end{array}$ & $94.7031 \%$ & $5.2969 \%$ & $\begin{array}{c}0.61 \\
\text { seconds }\end{array}$ \\
\hline $\begin{array}{l}\text { MultiBoost } \\
\text { AB }\end{array}$ & $96.9941 \%$ & $3.0059 \%$ & $\begin{array}{c}0.84 \\
\text { seconds }\end{array}$ \\
\hline
\end{tabular}

Table 6

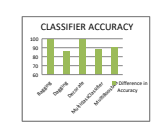

\section{Classification of Slight_Left_Turn}

Figure 4 Performance comparison for Slight_Left_Turn

The classification depends on the performance of the data to be classified. In this paper initially selected k-fold cross validation and some techniques are used. Estimating classifier accuracy is important in that it allows one to evaluate how accurately a given classifier will label future data. The main usage classifier is which it wraps to provide additional data preprocessing for feature selection accuracy. Some of the techniques for estimating classifiers are k_fold cross Validation methods and bootstrapping. A multi-layered approach for predicting the robot that moves forward or turn for better performance using different classifier methods to development is high efficiency; performance is to high and more accuracy. First stage is movement identification and the second stage is classification. The data is input in the first Stages which identify whether it is turn or move forward. Experimental results indicate that the proposed layered model with MetaClassifier on multiple dataset can be classified.

The Meta Classification Methods are Bagging, Dagging, Decorate, Multiclass Classifier and MultiBoostAB. Compared to all the Classifier Bagging is the best method for calculating the accuracy and it takes less time to build the model.

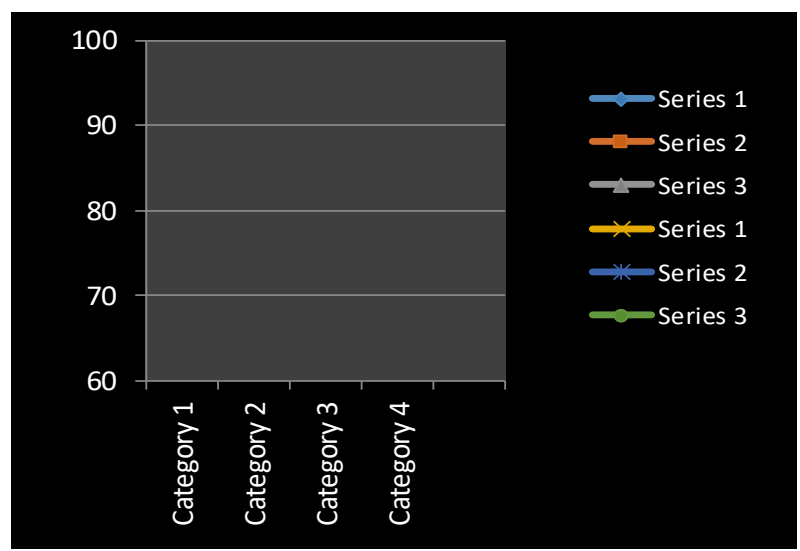

Figure 5 Performance comparison for three Layers

\section{RESULTS AND CONCLUSION}

We perform number of iterations on training and testing samples of selected robot's sensor data. Our approach will add strength to the robotic navigation for predicting the next step by not only the sensor but also the described predictions on patterns of navigations. Our results show the meta classifiers yield best accuracy for navigational path finding. A multi-layered approach for predicting the robot that moves forward or turns for better performance using different classifier methods that has been developed to achieve high efficiency and classification rate accuracy. The proposed system consists of two stages. First stage is movement identification. In the second stage for further classification. Experimental results indicate that the proposed layered model with one of MetaClassifier i.e. Bagging yields most accuracy in the evaluation.

\section{REFERENCES]}

1) G.R.Nudd, E. Papaefstathiou, et al., "A Layered Approach to the Characterisation of Parallel Systems for Performance Prediction: A Case Study", University of Warwick Publications Service \& WRAP”, 1994 http://wrap.warwick.ac.uk/60942/.

2) Ankita Gaur, Vineet Richariya, "A Layered Approach for Intrusion Detection using Meta-modeling with Classification Techniques", International Journal of Computer Technology and Electronics Engineering, vol. 1, Issue 2, pp. 161, 2011.

3) Peiman Mamani Barnaghi, Vahid Alizadeh Sahzabi, et al., "A Comparative Study for various Methods of Classification”, International Conference on Information and Computer Networks, vol. 27, 2011.

4) A.M. Kaptein, "Meta-Classifier Approach to Reliable Text Classification", Master's Thesis, Maastricht University, The Netherlands, 2005.

5) Wei-Hao Lin and Alexander Hauptmann, "Meta-Classifcation: Combining Multimodal Classifiers", In Osmar R. Zaiane, Simon Simoff and Chabane Djeraba editors, Mining Multimedia and Complex Data, Springer Verlag, 2003.

6) K.Rajiv Gandhi, S.M.Uma, et al., "A hybrid Meta Heuristic Algorithm for Discovering Classification Rule in Data Mining”, IJCSNS, vol. 12, no. 4, April 2012. 
7) Wei-Hao Lin, Rong Jin, et al., "Meta-Classification of Multimedia Classifiers",

https://pdfs.semanticscholar.org/1763/b65bc59fd7101ab818e16ed7029 70d728874.pdf

8) A.L.Freire, G.A. Barreto et al., "Short-term Memory Mechanisms in neural Network learning of Robot Navigation Tasks: A Case Study", Robotics Symposium (LARS), pp. 1-6, 2009.

9) P.Kalaiselvi, Dr.C.Nalini, "A Comparative Study of Meta Classifier Algorithms on Multiple Datasets", International Journal of Advanced Research in Computer Science and Software Engineering, vol. 3, Issue 3,pp. $654-659$, March 2013.

10) P.Kalaiselvi, Dr.C.Nalini, "Estimation of Association Mining to Determine the Performance of Apriori Algorithm”, IJAIR, vol.2, Issue 5, pp. 559 - 564, March 2013.

11) Kapil Kumar Gupta, Baikunth Nath, et al., "Layered Approach using Conditional Random Fields for Intrusion Detection", IEEE Transaction on Dependable and Secure Computing, vol. 7, I no. 1, pp. 35-49, January-March, 2010.

12) MahaLakshmi, "A Comparative analysis on persuasive meta classification strategy for web spam detection", International Journal of a Computer Science and Information Technology \& Security", International Journal of Computer Science and Information, vol. 2, no. 4, August 2012.

13) Pooja Thakar, Anil Mehta, et al., "Performance Analysis and Prediction in Educational Data Mining: A Research Travelogue", International Journal of Computer Applications, vol. 110, no. 15, January 2015, pp.60-68.

14) S.B.Kotsiantis, "Supervised Machine Learning: A review of Classification Techniques", Emerging Artificial Intelligence Application in Computer Engineering.

15) S.Vijayarani, M.Muthulakshmi, "Comparative Study on Classification Meta Algorithms", International Journal of Innovative Research in Computer and Communication Engineering", vol. 1, Issue 8, October 2013 pp.1768-1774.

16) S.Arun Enhanced Cyber Security for Big Data Challenges, International Journal of Innovative Technology and Exploring Engineering (IJITEE) ISSN: 2278-3075, Volume-8 Issue-10, August 2019

17) Padmapriya.S Design and Implementation of Autonomous Flower Harvester using Image Processing , International Journal of Recent Technology and Engineering (IJRTE) ISSN: 2277-3878, Volume-8 Issue-2, July 2019 